PUBLISHER CORRECTION

\title{
Publisher Correction: Low Antarctic continental climate sensitivity due to high ice sheet orography
}

\author{
Hansi A. Singh (iD) and Lorenzo M. Polvani (D) \\ npj Climate and Atmospheric Science (2021)4:14; https://doi.org/10.1038/s41612-021-00170-1
}

Correction to: npj Climate and Atmospheric Science https://doi.org/ 10.1038/s41612-020-00143-w, published online 8 October 2020

The original version of the Article contained errors in the figure captions of Figs. 3, 5 and 7, which incorrectly read ' $2 \mathrm{CO}_{2}$ ' and ' $2 \mathrm{CO}_{2} \mathrm{FA}^{\prime}$. The correct version read ' $2 \times \mathrm{CO}_{2}$ ' and ' $2 \times \mathrm{CO}_{2} \mathrm{FA}^{\prime}$ ', respectively.

The last sentence of the second paragraph of the Introduction incorrectly omitted a closing bracket and originally read '(Fig. 1; also see ref. ${ }^{13}$.'. The correct version reads '(Fig. 1; also see ref. $\left.{ }^{13}\right)$. .'

The second sentence of the third paragraph of the Introduction incorrectly omitted a closing bracket and originally read '(see, e.g., ${ }^{14-19}$.' The correct version reads '(see, e.g., $\left.{ }^{14-19}\right)$.'.

The last sentence of the first paragraph of the subsection 'Increased sensible heat advection with flattened orography' in Results incorrectly omitted a closing bracket and originally read '(Fig. 7 , compare contours in panels $a$, c with b, d; also see refs. ${ }^{15,22 .}$. . The correct version reads '(Fig. 7, compare contours in panels a, c with b, d; also see refs. $\left.{ }^{15,22}\right)$.'.

The last sentence of the third paragraph of the Discussion incorrectly omitted a closing bracket and originally read '(increased ocean heat convergence increases polar warming; see, e.g., ${ }^{35,36}$.' The correct version reads '(increased ocean heat convergence increases polar warming; see, e.g., $\left.{ }^{35,36}\right)$.'.

The third sentence of the second last paragraph of the Discussion incorrectly omitted a closing bracket and originally read '(as documented by ${ }^{53}$, . The correct version reads '(as documented by $\left.{ }^{53}\right)$, .
The first sentence of the first paragraph of the Methods incorrectly omitted a closing bracket and originally read '(CCSM4.0; see ref. ${ }^{58}$,'. The correct version reads '(CCSM4.0; see ref. $\left.{ }^{58}\right)$, .

The first sentence of the third paragraph of the Methods contained a redundant space and originally incorrectly read 'and (4) a $\mathrm{CO}_{2}-$ doubling experiment with flattened Antarctic orography'. The correct version reads 'and (4) a $\mathrm{CO}_{2}$-doubling experiment with flattened Antarctic orography'.

Finally, the second sentence of the third paragraph of the Methods contained phrases with incorrect cases and originally read '(see Table 1, Component set and configuration).'. The correct version reads '(see Table 1, Component Set and Configuration).'.

This has been corrected in both the PDF and HTML versions of the Article.

\footnotetext{
Open Access This article is licensed under a Creative Commons (cc) Attribution 4.0 International License, which permits use, sharing, appropriate credit to the original author(s) and the source, provide a link to the Creative Commons license, and indicate if changes were made. The images or other third party material in this article are included in the article's Creative Commons license, unless indicated otherwise in a credit line to the material. If material is not included in the article's Creative Commons license and your intended use is not permitted by statutory regulation or exceeds the permitted use, you will need to obtain permission directly from the copyright holder. To view a copy of this license, visit http://creativecommons. org/licenses/by/4.0/.
}

(c) The Author(s) 2021 